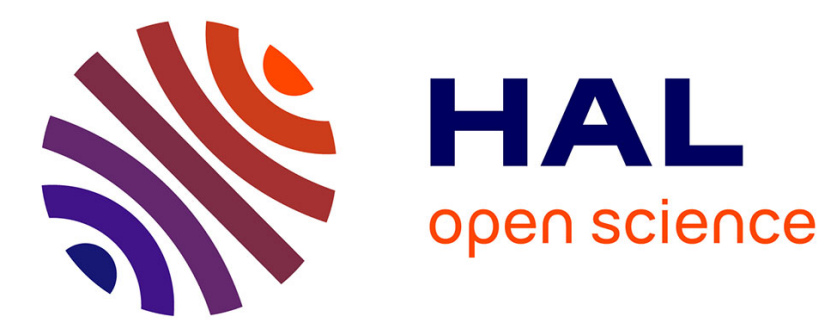

\title{
Conceptual Marketing In the Age of Interactive Consumer
}

Vladan Kuzmanović

\section{To cite this version:}

Vladan Kuzmanović. Conceptual Marketing In the Age of Interactive Consumer. Management, 2020, 3 (3), pp.21-32. 10.31058/j.mana.2020.33002 . hal-02913625

\section{HAL Id: hal-02913625 \\ https://hal.science/hal-02913625}

Submitted on 10 Aug 2020

HAL is a multi-disciplinary open access archive for the deposit and dissemination of scientific research documents, whether they are published or not. The documents may come from teaching and research institutions in France or abroad, or from public or private research centers.
L'archive ouverte pluridisciplinaire HAL, est destinée au dépôt et à la diffusion de documents scientifiques de niveau recherche, publiés ou non, émanant des établissements d'enseignement et de recherche français ou étrangers, des laboratoires publics ou privés. 


\title{
Conceptual Marketing In the Age of Interactive Consumer
}

\author{
Vladan Kuzmanovic ${ }^{1^{*}}$ \\ ${ }^{1}$ Faculty of Economics, University of Belgrade, Belgrade, Serbia \\ Email Address \\ vladankuzmanovic@yahoo.com (Vladan Kuzmanović) \\ *Correspondence: vladankuzmanovic@yahoo.com
}

Received: 28 December 2019; Accepted: 10 April 2020; Published: 27 May 2020

\begin{abstract}
:
Marketing is a system, a value, a complex. Marketing is a behavioral, interpersonal, and cultural concept. The value of total marketing is the value of the exchange of signs, labels, recognition, identity, trends, time and comfort. Contextual markets are complexes that are remarketed or resold in different iterative contexts, and under different circumstances. Marketing brings to the market a holistic system, the whole complex not just a part or a process.

Conceptual marketing deals with holistic entities. A context product is a marketing entity. The buyer also has the need for market reminiscences. The product complex includes the basic, extended, and external product.

The second part of paper debate my new Partnership model. The project is an intermediation because it is the relationship between the equilibrated actors who are in the process of optimizing their positions. However, individuals are actors of a whole personality, one partner has a privileged position but in the long term the equilibrium is sustainable.
\end{abstract}

\section{Keywords:}

Paramarketing; Referral Marketing; Complex Product; Relationship Marketing; Conceptual Marketing; Industrial Marketing; Contextual Markets; Partnership Model;

\section{Introduction}

Marketing is all in relation with marketing. Marketing are ancillary activities and para-activities. Cultural marketing, market art, concepts of markets, market habits market ambiences and market acts.[1] At the beginning of the century, an interesting approach to freakonomics emerged [2] from all that it produced as a by-product of economics. Economics is the whole complex not only the focus, economics is at the very least a civilizational culture (economic behavioral culture), not just a social phenomenon, a set of social activities. [3][4][5] Furthermore, with the development of marketing, a whole series of marginal disciplines and marginal concepts emerged. Instead of a multidisciplinary managerial approach, transdisciplinary phenomena come forth, exempli gratia between market art and marketing art, or marketing concept and market concept, etc. Conceptual marketing in this case refers to much 
more than a marketing concept - it is a concept of marketing and namely conceptual marketing. By "conceptual marketing" we mean a conceptual act, or conceptual activity as a border category.

Once the price as a market activity is formed or tendered as a conceptual act it is by all mean market price. Price is a marketing concept not a factor. The price act refers to price as a conceptual, experimental value. Price is not a variable but a concept or attitude. An actor is a bidder or price creator, as a product. Price is a product. Price is a product on offer, price is a concept. In a series of non-artistic topics, an economic objects occur: brands, logos, labels, articles, commodities. [5] The basis of pop art is the one of economic phenomenon - consumerism. Artecon is everything from mass design to high art. Forth on art becomes a design concept instead of expendable design.

\section{Total marketing and complex product}

Design and price are concepts of new border discipline - marginal or boarder marketing. Non-market act, non-price mass distribution, mass distribution from nonmarketing to paramarketing activities, etc. Marketing is everything except what is not marketing. Non-marketing is marketing, where marketing is used as a relational phenomenon. As Baudrillard suggests [6], consumption is increasingly becoming a productive process, goal-oriented, and purposeful; furthermore, it requires that individuals be educated to carry out this process. In customizing oneself to (re)present marketable (self-)images, the consumer is interacting with other objects in the market to produce oneself, to purposefully position oneself. In this production process of the self-image(s) 'the consumer also acts as the marketer of self, selecting to use and interact with different other products that fit and enhance the image to be cultivated in each situation. Paramarketing encompasses a whole range of para-marketing activities which do not constitute mainstream marketing yet are closely related to the marketing culture. [6] Paramarketing is a consumer-mediated activity and refers to the immediate experience of (co) lateral market experiences. Paramarketing is a set of para-activities. Para-marketing is a consumer-mediated activity, marketing itself is seen from the consumer's point of view as an object of offer. [6] Marketing's role in contemporary culture can best be understood by placing it into the system of exo/esomodernities. The market, and marketing as its institutionalized set of practices, has become a key institution of modern culture. Marketing does not create a concept / consumption, but a concept that is also an object of consumption.

Marketing is a system, a value, a complex. Marketing is a behavioral, interpersonal, and cultural concept. [5] The value of total marketing is the value of the exchange of signs, labels, recognition, identity, trends, time and comfort. [7][8] Marketing consists of a set of brands, labels, logos, cultural patterns, communicative processes and interpersonal relationships. The complex product represents the overall marketing effect, not just the economic, segmental, targeted or lateral effects of marketing.

Total marketing is a set of activities related to a complex product and involves planning, creating, concepting, registering and reusing of product complex. Total marketing involves revaluation, interaction, enhancement of utility as a transfer in progressive marketing model.

\section{Conceptual Marketing}


Marketing itself can be a need, in addition to dealing with needs. Imediation of marketing for marketing as a subject of marketing, remarketing of market and wider, overall, social effect of marketing.

In addition to the basic goal - finding the need, marketing also generates other goals, which generally oriented to increasing customer convenience through a marketing environment and a set of referral values.

Total marketing includes basic, extended and referral marketing, which recalibrates conventional marketing by resetting the entire process as a new process offering. Classical marketing referral is about activity correction. The use of marketing as a form is represented through conceptual marketing: once realized, the marketing process becomes a form that can be sold, changed and offered.

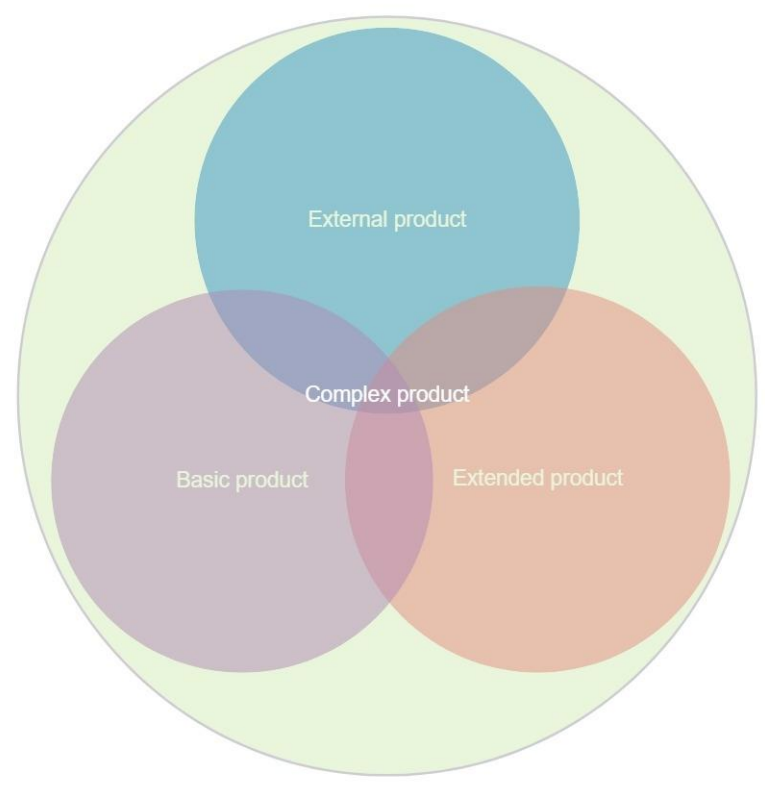

Figure 1. Product Complex consisting of basic, extended and external product.

Contextual markets are complexes that are remarketed in different iterative contexts, and under different circumstances. Seller brings to the market a holistic system, the whole complex not just a part or process. Conceptual marketing deals with holistic entities. A context product is a marketing entity. Customer perception is a metanarrative. The buyer also has the need for market reminiscences. The product complex includes the basic, extended, and external product (Figure 1).

It seems that postmodernism is no longer a theory or a philosophical stance but a reality which impacts upon many facets of life in, specifically, Western societies. It is represented in world views which are increasingly becoming prominent, and also in the conditions, such as, hyperreality, fragmentation, decentring of the subject, reversal of production and consumption, paradoxical juxtaposition of opposites, and noncommitment to meta-narratives. [9] 
An external product is reffered to the position and interaction of the product in a marketing environment. The marketing environment is the practice of the customer to value non-economic phenomena / variables as economic, according to their market experience, habits, profile attitude or feelings.

The external product primarily involves a large number of paramarketing activities as consumer habits and behavioral processes.

Just few examples of hobby marketing activities, and the hippie marketing subculture. The phenomenon of fanacons began in the early 1970s in America. Antimarketing, anti-shopping, and a whole host of deviant three-way behaviors, originated in response to consumerist culture. [10][11][12]

In some Western countries, buying is seen as a ritual, and more, as a cult, and the buying process itself is implemented as a performance, subversion, or sentimental act. The buyer is proactive or deactive, the buyer is not only delaying specific marketing messages or incentives. [13][14] Purpose-innovative consumers are an important market segment. [15][16]

Para-shopping is activity of buying irrelevant, unnecessary and unwanted things, buying out of the mainstream, deliberately buying non-advertised goods, including superficial and collateral shopping, with a selection of less desirable and less important items as an act.

The concept of recreational shopper identity, a dimension of the consumer's selfconcept, is contrasted with simple shopping enjoyment, which has characterized most past research on recreational shopping. Recreational shopping enthusiasts are found to engage more extensively in a range of retail shopping behaviors, to spend more money shopping (i.e., they are not just browsers), and are more "multi-channel" than other shoppers. [16]

A collected object becomes a reminder of the story of its acquisition. The object is, thus, a cue for recalling and retelling this story. The images that a collection conjures up may therefore be a part of the collector's personal history of times and places. Stewart calls these associations "souvenirs" (because of their metonymic authentication of the past) and distinguishes them from collections (which she contends involve only a metaphoric derivation of authenticity from the past). However, we consider personal history to be an inescapable part of collections. "it is as if the experience of possession could be transformed into the possession of experience". [17]

Affiliate marketing takes place between the buyer and the seller, the result is a surefire effect, greater than expected, in deact or proact, irrational rationality, dynamic marketing relationship, a recognizable affect versus effect. The customer subjectively responds to objective influences. [18] The buyer is creative, which means that he does not only respond formally to marketing stimuli. Objective influences always expect objective reactions, however reactions are subjective, behavioral. The solution to this is in subjective stimuli, in a one-to-one project marketing relationship.

\subsection{Fanecon}

Fanecon is a person who lives on very margings of marketing culture, collect labels, promos, business leaflets, brands and other marketing staff, and is passionate collector of market brands, pamphlets and generic products. He is multi obsessionist even an art lover, expert in brand history, unusual economic facts, rare currencies, company 
logos, economic eccentricities collector, marketing culture enthusiast who enjoys the abundance of propaganda material, or just is rapt with objects.

Fanecons have in some sense made a mark in marketing culture with the advent of hippie culture and consumerism branding and marketing expansion in the 70's. Fanecon binds to specific brand products or is experimenting with brands. Fanecon is a sub-cultural consumer. Fanecon is a consumer of the time market. And, why not, fanekon is a proactive consumer. [19][20]

Brand culture refers to the cultural influences and implications of brands in two ways. First, we live in a branded world: brands infuse culture with meaning, and brand management exerts a profound influence on contemporary society. Brand culture represents one interdisciplinary framework for understanding how brands create value and meaning. Second, brand culture provides a third leg for brand theory - in conjunction with brand identity and brand image, brand culture provides the necessary cultural, historical and political grounding to understand brands in context. Future consumer research on visual issues must acknowledge images' representational and rhetorical power both as cultural artefacts and as engaging and deceptive bearers of meaning, reflecting broad societal, cultural, and ideological codes. [21][22] A brand community is a specialized bound community based on a structured set of social relations among admirers of a brand. Muniz [25] uses ethnographic and computer mediated environment data to explore the characteristics, processes, and particularities of three brand communities (those centered on Ford Bronco, Macintosh, and Saab). These brand communities exhibit three traditional markers of community: shared consciousness, rituals and traditions, and a sense of moral responsibility.

Economics is not a disciplinary approach, but a disciplinary fundability instead. Discipline is in this new order of things, a concept, not projection but output, effectuation. Instead of bijection, there is an inversion of concepts, instead of a variable concept - a concept variable. Price concept - concept price, design concept concept design, market concept - concept market, marketing concept - conceptual marketing, active concept - concept activity. Conceptual marketing consists of concepts that are not aspects but economic projects; each discipline is a concept or project - behavioral, psychological, cultural, communicative, etc. [23]

\section{Project as an exchange process}

The activities of the individuals should be summarized as a project. Marketing is an active project. Marketing is ultimately conceived as an economic project toward everything. Marketing is an economic project. The firm is understood as a set of individual activities. After all, is marketing an individual activity? If it wants to determine responsibility, if it wants to accomplish a task, set goals that an actor of a certain system should accomplish. The set goals are not projections (as in the classical scheme) but projects. This means that activities are viewed by individuals as their own capabilities, they do not mediate them but rather recognize them.

Activities are an internal set of goals and activities effectuate individuals. In a firm, activity is understood as a project, and the individual is motivated to accomplish the task. If he accomplishes the task, he is realized not only as an employee, but also as a personality. Personality has far greater potential than non-personality, employee. The projection does not go from operator to operator (or function holder to function holder) in delegating responsibilities, but from individual to individual and from project to project (as in a dynamic set). The organization consists not of a set of 
projections but a set of bijections, the company is based on the integrity of mutual projects. Project of one individual is project of another individual. Thus relationships are structured, but there are no basic problems in project marketing: detraction, demotivation, abuse, isolation, formalism, pressure, deception. The problem of efficiency arises as a result of psychological factors. The individual does not subsequently activate for the benefit of the company because the firm does not see them as an individual but as a operator. Individuals are driven by economic motives. The problem is that motives are in conflict with organizational goals; individual motives are in discrepancy with economic principles; employee perceives principles as something that in opposition to his own motives and wants. In empirics, there is a tacit collision of individual motives and economic goals.

In the firm, there is a diseconomy between individual and general goals. The overall goals are latent projections. The economy is plagued by the problem of economic communication. Therefore it proved necessary to grasp form as content, there is a formal tension that leads to a further decline in efficiency. Economic individuals are frustrated and just formally functional.

Psychological marketing is a powerful tool in the cases of formal tension. Organizational output is a synergy of individual activities. First of all, consumers are seen as internal customers. In the concept of individual marketing, employees are seen as internal customers and external customers as customers. The relationship of the project organization is externalized, the relationship is purely individual, direct communication between individuals as system actors. Economic interaction is individual. The project that engages the employee also realizes the customer. As postpurchase activity, satisfaction is a firm-employee-customer relationship. The firm is formed from a triple customer-employee-firm relationship, and effectiveness is understood as a fine outcome. In marketing, goals are aligned, safisfaction is interactive and mutual. If there is no win-win option in the long term, a weakening, dissatisfaction with relationships, loss of loyalty, and a decline in efficiency. Relationships are a win-win economic option. An actor relationship of actors is a partner relationship. So a project is a relationship between two or more economic partners, as economic agents of a particular activity; there must be fine-tuning between economic partners, finally the relationship is an exchange. [24]

Staff unit managers in a range of disciplines who want to better serve internal publics can effectively market their services internally by understanding and responding to internal decision processes and expectations.

The terms "internal relationship marketing", "internal relationship management", or "internal social process management" are proposed as a development of other terms used by the writers discussed. These new terms recognise the applicability of the marketing concept through the identification of (intra-organisational) exchanges in working relationships and between the organisation and its customers, since "all employees are customers of managers who wish to carry out the firm's objectives". [24]

Internal marketing is . . . an important activity in developing a customer-focused organisation ... Fundamental aims of internal marketing are to develop internal and external customer awareness and remove functional barriers to organisational effectiveness. 
From this conceptual review, a number of themes have been identified as offering a contribution to the development of a more sophisticated and valuable conception of internal marketing. These themes are:

. marketing-oriented service employee management;

. marketing as exchange;

. organisation as a "domesticated" (internal) market;

. internal marketing as a social process;

. a relational perspective on communication;

. internal marketing as a new form of industrial relations. [25]

The consumer is part of the company, the customer is on both sides. The goal is not one-sided customer satisfaction, but mutual satisfaction. Marketer dissatisfaction may reflect on customer satisfaction in subsequent iterations of purchase, in the long run. The marketer, on the other hand, can pass the dissatisfaction on to the buyer.

This broadened theory of internal marketing may be further elaborated on as a goaloriented social process, and a conceptual system for continually creating rapid strategic organisational change in response to the macro-environment (society) and the micro-environment. [25]

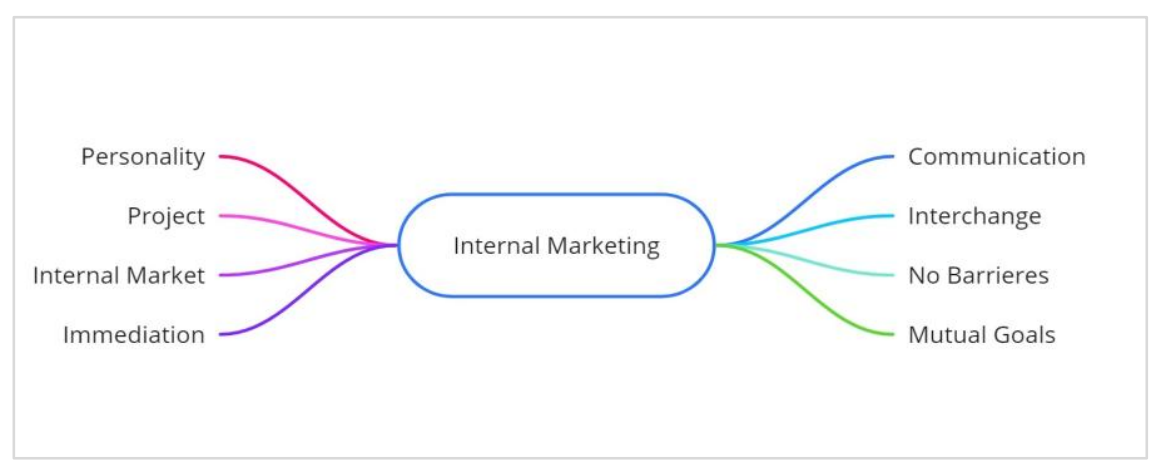

Figure 2. Internal Marketing mindset.

All employees are sellers of satisfaction services. [26] The relationship that is valid in the company is also the relationship outside the firm, towards third parties. [27] Relationship in the company and the relationship outside the company is an exchange, a project, a customer is a part of the company in the long run. [26] Each customer is an investor in the company. The relationship is immediate and psychologically profiled. The relationship between buyer and seller is first and foremost an intermediation. In the mediation, the customer expresses his needs directly. Due to the fact that the needs are irregular, the relationship is immediate. Immediate relationship arises from the immediation of needs (Figure 2).

Furthermore, economic relationship is an exchange, this can only be answered by an immediate response, immediate satisfaction as a service, at the customer's request. Immediate service is an answer to an immediate need. The relationship consists of at least two requests and two answers. In the model outlined here, the economic relationship is the exchange of requests and answers (satisfaction).

Relationship-project is an exchange of immediate requirements and immediate safisfaction. A project is an economic transaction, a relationship is an economic, 
interactive dynamic transfer between partners as actors. The project is an intermediation because it is the relationship between the equilibrated actors who are in the process of optimizing their positions. The economic act is not isolated outside the project and is understood as a process. Sales are a set of acts that are not isolated but create a system of immediate consumption. In terms of satisfaction both actors have identical starting positions. However, individuals are actors of a whole personality, one partner has a privileged position but in the long term the equilibrium is sustainable.

Optimization is achieved in a series of individual equilibriums, transfers of fair satisfaction. The economic effect of partner transfer is greater because of synergy, greater mutual benefit, and intersatisfaction (in addition to intrasatisfaction of classical exchange). Positions are promoted and aligned with iterative acts with the need for an optimal position. Optimization is achieved only when both actors maximize their satisfaction. Satisfaction is an exchange of economic type. Thus, it is only at the optimal equilibrium, that satisfaction is maximized. The actors are looking through a set of harmonized experiences for the most favorable mutual position, as a project. With the partnership being actively mildly asymmetrical. One partner has bigger requirements, while the other one meets the requirements. However, both are aware of long-term mutual satisfaction in terms of positive addiction. A partnership is not a monopoly but a loyalty. Conditionality and dependence are not possible in a substantive and decisive way in a project. Conditionalities are dynamic incentives and mutual partner dependency is a flexible mechanism. [28][29]

Long-run equilibrium curve, and the individual satisfaction curve oscillates around the long-run economic equilibrium curve. One partner has a privileged position (slightly greater satisfaction than the other partner's safisfaction; more satisfaction with it). In the next iteration, the satisfaction is equalized, equilibrated, a new disquilibrium in a more favorable position brings the partner who satisfied the other partner in the previous transfer. [30][31]

An economic equilibrium, a transfer relationship, makes a set of mutual concessions and benefits. The long-term satisfaction curve tilts slightly in favor of one of the partners, in an asymmetric equilibrium situation characterized by iterative transfers. Aggregately, a set of win-win situations is made up of sub-sets of frequent win-win, win-lose and lose-win market affiliate transfers. The relationship is a tuning set. Transfer is a process of matching needs. The project is interaction. With both parties actively engaged. Customers actively participate in the satisfaction process, they are being progressively complied with. The satisfaction process is dynamic. Satisfactions are short-term, benefits are long-term. Satisfactions are short-term and renewable, thus their equilibrium is long-term. i) satisfaction is exchange, that is, transfer. In order to achieve a transfer between actors, ii) safisfaction is an active interaction because it pleads for a long-term effect. The project involves the active interaction of partners, the classic consumption of actors involves only one actor who is: passive, privileged, non-engaged, non-interactive and unproductive; however, transfer is a production, versus a projection of short-term transfer (satisfaction), the long-term benefit of transfer is valid.

Current competitive pressures require organizations to adopt a higher degree of market orientation for their projects and to build and maintain strong relationships with their stakeholders, customers, financial and political backers, and the general public. [32][33] [34] 
Project participants need to identify, anticipate, and satisfy customer requirements and to satisfy customers' needs through a process of exchange. [35][36]

\section{The partnership model}

Participants in the process do not act as actors but as partners, aiming to secure the partner's win position not only their own win, in the long term. In the relationship model, satisfation is derived and reciprocal. The transfer model explicates about immediate and altruistic, mutual benefit. Both partners will achieve the long-term goal only after two iterations have been completed. After the buyer's safisfaction has been achieved, which has resulted in the seller's safisfaction. Repeated purchase and repeated satisfaction, repeated purchase is the result of a project relationship, that is, customer satisfaction that has led to seller satisfaction.

The thing about interactive consumption is that the saturation is not repeated but increased. The thing about satisfaction is that once achieved satisfaction wants to be repeated, however, repeated satisfaction does not contain the same level of satisfaction as the previous one, but diminished. Repeated consumption is effected at a lower level of satisfaction due to the effects of the principle of saturation. Expected satisfaction is not a real satisfaction either, due to the fact that satisfaction is relative rather than absolute. Satisfaction is the degressing absolute satisfaction of the consumption process. However, real satisfaction is a progressive relative contentvariable of the interactive process (Figure 3).

Expected satisfaction is a progressive variable of the interactive process. Economic transfer is a relationship in which the exchange of satisfaction takes place between the two actors involved in the process. Process is a relationship of mutual satisfaction. Increasing satisfaction is positively correlated with increasing utility.

An interactive relationship is a transfer of progressive satisfaction. The involvement of both partners ensures a positive long-term relationship. The relationship on its part is a progressive, reciprocal relationship. The project relationship is about: customer benefit, customer-customer relationship, communicative transfer, expected real satisfaction, interactive benefit, partners as economic actors, fine tuning, maximizing individual satisfaction, (slightly) asymmetric partnership, coming through a series of iterative transfers to the long-term equilibrium of optimal individual preferences (See Figure 4). [35] 


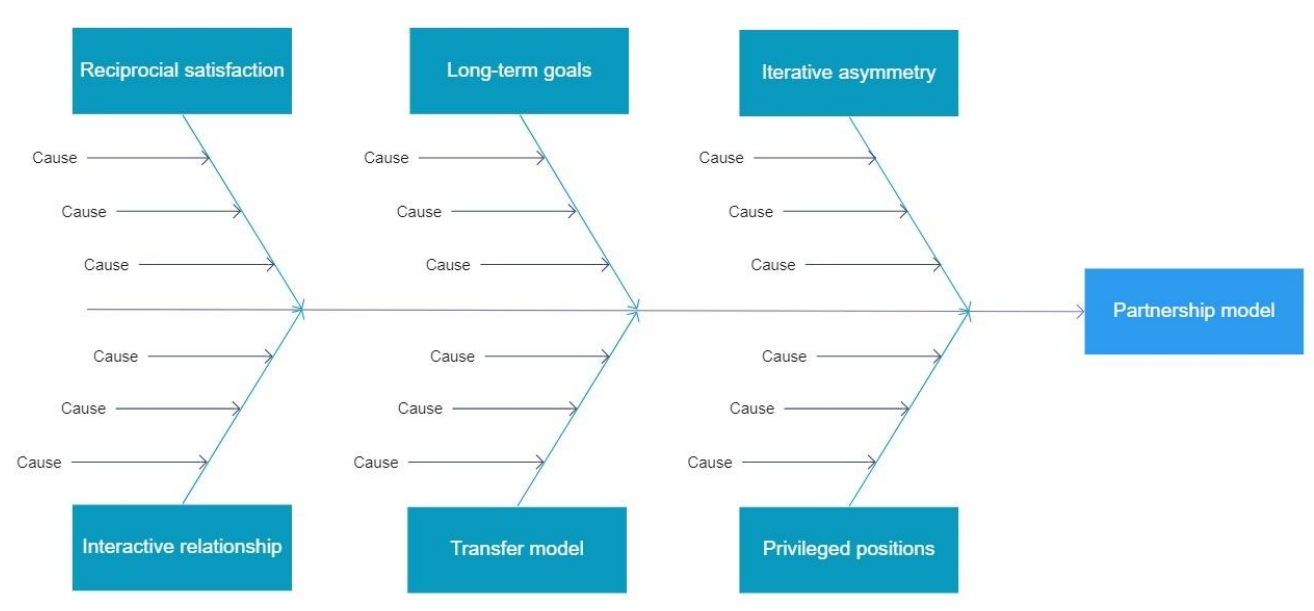

Figure 3. General Partnership Model

Preferences are exchanges between satisfaction, pursuit of privileged positions, increased positive economic effects, in this case two-sided benefits as a long-term relationship, privileged benefits, exchange of privileged positions, if the parities are asymmetrical they are iteratively exchanged through a set of iterative pursuits, to optimal position- long-term equilibria.

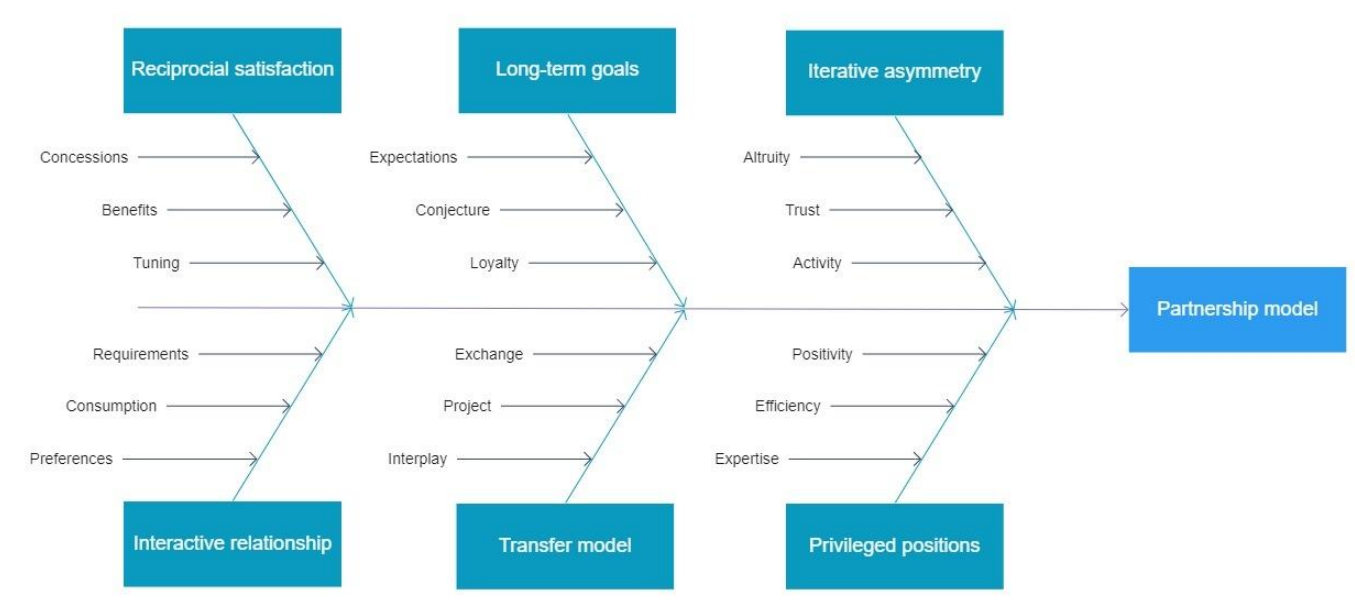

Figure 4. Partnership model with optimal traits and motivational forces.

Profitably targeted as a long-term variable, the long-term benefit derives from the relationship of maximizing the individual satisfaction of actors in the process. The project is not a classic buyer-seller relationship. The projecter is an active stakeholder relationship in the exchange process. [31][36][38]

Employees are actors, as well as customers. A firm is a structure consisting of a group of economic actors in the transfer process. Interactive transfer is a positive effect, 
which means that it provides progressive benefit / satisfaction. Economic transfer (firm) is characterized by communication and participation. The firm is the relationship of all partners in the process. [39][40]

\section{Conclusion}

Expected satisfaction is a progressive variable of the interactive process. Economic transfer is a relationship in which the exchange of satisfaction takes place between the two actors involved in the process. Process is a relationship of mutual satisfaction. Thus, it is only at the optimal equilibrium, that satisfaction is maximized. The actors are looking through a set of harmonized experiences for the most favorable mutual position, as a project.

With the partnership being actively mildly asymmetrical, one partner has bigger requirements, while the other one meets the requirements. However, both are aware of long-term mutual satisfaction in terms of positive addiction. A partnership is not a monopoly but a loyalty. Conditionality and dependence are not possible in a substantive and decisive way in a project.

Conditionalities are dynamic incentives and mutual partner dependency is a flexible mechanism.

\section{Conflicts of Interest Copyright}

The author declare that there is no conflict of interest regarding the publication of this article.

\section{Acknowledgments}

The Author wish to thanks the Editor of the Journal and Colleagues for Helpful comments.

\section{Copyright}

(C) 2019 by the author. Licensee International Technology and Science Press Limited. This article is an open access article distributed under the terms and conditions of the Creative Commons Attribution (CC BY) License, which permits unrestricted use, distribution, and reproduction in any medium, provided the original work is properly cited.

\section{References}

[1] Janssen, M. A.; Jager, W. Fashions, habits and changing preferences: Simulation of psychological factors affecting market dynamics. Journal of economic psychology, 2001, 22(6), 745-772.

[2] Levitt, S.D.; Dubner, S. J. Freakonomics. New York: William Morrow, USA, 2005.

[3] Eun Park, J.; Yu, J.; Xin Zhou, J. (2010). Consumer innovativeness and shopping styles. Journal of Consumer Marketing, 2010, 27(5), 437-446. 
[4] Turley, L.W.; Milliman, R. E. Atmospheric effects on shopping behavior: a review of the experimental evidence. Journal of business research, 2000, 49(2), 193-211.

[5] Tian-si, W.A.N.G. An Investigation into the Marketing Civilization [J]. Hebei Academic Journal, 2003, 1.

[6] Firat, A.F.; Dholakia, N.; Venkatesh, A. (1995). Marketing in a postmodern world. European journal of marketing, 1995, 29(1), 40-56.

[7] Baudrillard, J., in Poster, M. (Ed.), Selected Writings, Stanford University Press, Stanford, CA, 1988.

[8] Ogilvy, J. This postmodern business. Marketing and Research Today, 1990, 18(1), 4-20.

[9] Firat, A.F. Marketing: culture institutionalized. Journal of Macromarketing, 2013, 33(1), 78-82.

[10] Barksdale, H.C.; Darden, W.R. Consumer attitudes toward marketing and consumerism. Journal of Marketing, 1972, 36(4), 28-35.

[11] Kangun, N.; Cox, K.K.; Higginbotham, J.; Burton, J. Consumerism and Marketing Management: How do consumers perceive consumerism... and what are the implications of these perceptions for marketing managers? Journal of Marketing, 1975, 39(2), 3-10.

[12] Firat, A.F. Postmodernism and the marketing organization. Journal of Organizational Change Management, 1992.

[13] Aaker, D.A.; Day, G.S (Eds.). Consumerism. Simon and Schuster: New York, 1982.

[14]d'Astous, A.; Maltais, J.; Roberge, C. Compulsive buying tendencies of adolescent consumers. ACR North American Advances, 1990.

[15] Youn, S.; Faber, R.J. Impulse buying: its relation to personality traits and cues. ACR North American Advances, 2000.

[16]Bellenger, D.N. Profiling the recreational shopper. Journal of retailing, 1980, 56(3), 77-92.

[17]Reynolds, K.E.; Ganesh, J.; Luckett, M. Traditional malls vs. factory outlets: comparing shopper typologies and implications for retail strategy. Journal of Business Research, 2002, 55(9), 687-696.

[18] Guiry, M.; Mägi, A.W.; Lutz, R.J. Defining and measuring recreational shopper identity. Journal of the Academy of Marketing Science, 2006, 34(1), 74-83.

[19]Belk, R.W.; Wallendorf, M.; Holbrook, M.B. (1991). Collecting in a consumer culture. ACR Special Volumes.

[20] Kotler, P. From sales obsession to marketing effectiveness (pp. 1-9). Graduate School of Business Administration, Harvard University, 1977.

[21] Beatty, S.E.; Ferrell, M. E. Impulse buying: Modeling its precursors. Journal of retailing, 1998, 74(2), 169-191.

[22] Youn, S.; Faber, R. J. Impulse buying: its relation to personality traits and cues. ACR North American Advances, 2000. 
[23] Schroeder, J.E. Brand Culture: Trade marks, marketing and consumption. In Trade marks and brands: An Interdisciplinary critique; Jane Ginsburg, Lionel Bently and Jennifer Davis, eds., Cambridge University Press, 2008; pp. 161-176.

[24]Cox, K. K.; Higginbotham, J.; Burton, J. Consumerism and Marketing Management: How do consumers perceive consumerism... and what are the implications of these perceptions for marketing managers?. Journal of Marketing, 1975, 39(2), 3-10.

[25] Muniz, A.M.; O'guinn, T.C. Brand community. Journal of consumer research, 2001, 27(4), 412-432.

[26] Harrell, G.D.; Fors, M. F. Internal marketing of a service. Industrial Marketing Management, 1992, Vol. 21 No. 4, 299-306.

[27] Varey, R.J.; Lewis, B.R. A broadened conception of internal marketing. European Journal of Marketing, 1999, 33(9/10), 926-944.

[28]Zwick, D.; Cayla, J. (Eds.). Inside marketing: Practices, ideologies, devices. Oxford University Press, 2011.

[29] Sweeney, D.J. Marketing: management technology or social process? Journal of Marketing, 1972, Vol. 36, 3-10.

[30] Campbell, A.J.; Cooper, R.G. Do customer partnerships improve new product success rates?. Industrial Marketing Management, 1999, 28(5), 507-519.

[31] George, W.R. Internal marketing and organizational behavior: A partnership in developing customer-conscious employees at every level. Journal of Business research, 1990, 20(1), 63-70.

[32] Martin, D.P.; Hunt, J.R.; Conrad, D.A.; Hughes-Stone, M. The Planetree model hospital project: An example of the patient as partner. Hospital \& health services administration, 1990, 35(4), 591-602.

[33]Perks, H.; Easton, G. Strategic alliances: partner as customer. Industrial Marketing Management, 2000, 29(4), 327-338.

[34] Kotler, P.; Levy, S. J. Broadening the concept of marketing. Journal of Marketing, 1969, Vol. 33, 10-15.

[35] Odekerken-Schröder, G.; De Wulf, K.; Schumacher, P. Strengthening outcomes of retailer-consumer relationships: The dual impact of relationship marketing tactics and consumer personality. Journal of business research, 2003, 56(3), 177190.

[36]Pinto, J.K; Rouhiainen, P.J. Building Customer-Based Project Organizations; Wiley: New York, 2001.

[37]Dalcher, D. Requirements management. In J.R. Turner (Ed.), The Gower Handbook of Project Management (5th ed.); Aldershot: Gower, 2014.

[38]Lecoeuvre, L.; Turner, J.R. Project Marketing By Three Organizations: Marketing By, For, And Of The Project. Paper presented at Project Management Institute Research and Education Conference, Phoenix, AZ. Newtown Square, PA: Project Management Institute, 2014.

[39] Franco, J.J. Customer satisfaction: the partnership imperative. Training \& Development Journal, 1990, 44(7), 80-83. 
[40] Cascio, W.F. From business partner to driving business success: The next step in the evolution of HR management. Human Resource Management: Published in Cooperation with the School of Business Administration, The University of Michigan and in alliance with the Society of Human Resources Management, 2005, 44(2), 159-163.

(C) 2019 by the author(s); licensee International Technology and Science Publications (ITS), this work for open access publication is under the Creative Commons Attribution International License (CC BY 4.0). (http://creativecommons.org/licenses/by/4.0/) 